\title{
Simulasi Pengisian Air Ketel Menggunakan Rangkaian IC Gerbang Logika Dasar Sesuai di MV. Tanto Setia
}

\author{
Kurniawan $^{\mathrm{a}}$, Wahyudiono $\mathrm{A}^{\mathrm{b}}$, Purwantini $\mathrm{S}^{\mathrm{c}}$ \\ abcPoliteknik Ilmu Pelayaran Semarang. \\ aEmail: 104.ardhikurniawan@gmail.com \\ bEmail: awahyudiono64@gmail.com \\ 'Email: purwantinisri66@gmail.com
}

\begin{abstract}
ABSTRAK
Sebuah sistem pengendalian diperlukan untuk mengisi air di dalam ketel. Sistem pengendalian ini menggunakan rangkaian integrated circuit gerbang logika dasar. Terdapat berbagai langkah untuk membuat sistem pengendalian pengisian air ketel. Sistem pengendalian ini akan disimulasikan menggunakan rangkaian integrated circuit yang dapat dijalankan secara otomatis dan manual. Tujuan penelitian ini adalah mengetahui cara pembuatan simulasi pengisian air ketel menggunakan rangkaian integrated circuit gerbang logika dasar yang dapat dioperasikan secara manual ataupun otomatis seperti di kapal MV.Tanto Setia.Metode penelitian yang digunakan yaitu metode deskriptif untuk menggambarkan dan menguraikan proses pembuatan alat simulasi pengisian air ketel serta teori-teori yang berhubungan dengan pengendalian alat tersebut. Eksperimen dan pengamatan secara langsung dilakukan dalam proses pembuatan pengendalian alat agar sesuai yang diharapkan.Hasil pembuatan simulasi pengisian air ketel menggunakan rangkaian IC NOR 4001. Pengisian air ketel ini di pengaruhi oleh sensor water level. Tetapi sensor tak berpengaruh jika pengendalian mode manual. Rangkaian menggunakan integrated circuit gerbang logika dasar lebih sederhana dan cepat dimengerti bagi pemula.
\end{abstract}

Kata kunci : Simulasi, Gerbang logika, MV.Tanto Setia

\section{ABSTRACT}

Filling up water for boiler need a control system for fill up the water into the boiler. This control system using integrated circuit with the logic gates. there is some way for make the control system for boiler water fill up. This control system will be simulated using the integrated circuit that can operated by manual or auto. The purpose of this study is knowing how to make boiler water filling up simulation using integrated circuit logic gates that can operated by manual or auto like in the MV.Tanto Setia. Study methodes that we use is descriptive method for describe and explain the process of make the simulation toolsfor boiler water fill up also the theory that connect with controlling the tools. Experiments and savings are directly carried out in the process of making tool control to match what is expected. The result of this simulation using circuit IC NOR 4001 Boiler water fill up effected by water level sensor. But the sensor will not effect if the control put to manual mode. The integrated circuit more easy to understand for the beginner.

Keywords : Simulation, Logic gate, MV.Tanto Setia

\section{PENDAHULUAN}

Ketel uap adalah sebuah bejana tertutup pembentuk uap pada tekanan lebih besar dari 1 atmosfer atau 1 bar. Apabila air dipanaskan di dalam tabung tertutup tersebut oleh gas-gas panas yang dihasilkan dari pembakaran bahan

https://doi.org/10.46484/db.v1i1.177 bakar dalam dapur ketel, maka uap-uap panas bertekanan tinggi akan dihasilkan. Hasil ketel uap adalah uap yang bertekanan tinggi dan panas yang cukup tinggi (Jusak; 2016).

Boiler (ketel uap) adalah suatu alat (mesin) yang berfungsi untuk 
pembangkit tenaga, adapun jenisnya ada tiga yaitu ketel pipa air, ketel pipa api dan ketel kombinasi. Untuk membangkitkan uap ketel ini terdiri dari beberapa bagian dimana tiap bagian mempunyai fungsi berbeda. Boiler sebagai alat penukar kalor yang harus memenuhi syarat primer, yaitu ketel uap harus dapat menyediakan sebanyak mungkin dengan tekanan dan suhu tertentu yang telah ditentukan serta dalam penggunaan bahan bakar harus bisa serendah mungkin (Murni; 2012)

Saat beroperasi ketel ini harus selalu terisi air di dalamnya. Jangan sampai saat pengisian air melebihi batas maksimal karena hal ini akan mempengaruhi produksi uap pada ketel tersebut. Pengisian air ketel menggunakan pompa yang digerakkan oleh motor listrik. Cara kerja pengisian air ketel adalah menerima permintaan atau intruksi dari pengguna untuk menggerakan pompa. Dengan adanya permintaan dari pengguna maka dibutuhkan perancangan alat kendali pengisian air ketel. Untuk memahami prinsip perancangan diperlukan adanya pemahaman teori-teori dasar yang terbentang dari elektronika dasar, rangkaian analog, rangkaian digital. Pada pendesain rangkaian digital terdapat pula bagian-bagian ilmu yang harus dikuasai seperti sistem bilangan gerbang logika. Gerbang logika dasar adalah gerbang yang memiliki 2 input (masukan) dan 1 output (keluaran) (Helmi dan Ikhsan; 2017).

Suatu rangkaian terpadu (integrated circuit) adalah sebuah kristal silikon kecil yang disebut chip mengandung komponen elektronika seperti transistor, dioda, resistor, dan kapasitor. Komponen itu saling dihubungkan dalam chip membentuk suatu rangkaian listrik tertentu (Beuaty, et al; 2009)

Perangkaian gerbang logika dasar dengan simulasi dapat membantu dalam pembuktian teori-teori yang ada (Ikhsan, dan Siti; 2018). Gerbang logika AND dan OR tersedia dalam kemasan sebagai integrated circuit. Tata letak pin integrated circuit, tipe gerbang logika dan spesifikasi teknik semuanya termuat dalam manual data logika yang disediakan oleh pabrik pembuat dari integrated circuit tersebut.

Terdapat 7 jenis gerbang logika dasar yang membentuk sebuah sistem elektronika digital yaitu gerbang AND, gerbang OR, gerbang NOT, gerbang NAND, gerbang NOR, gerbang X-OR, dan gerbang X-NOR. (Wijaya; 2006).

Resistor disebut juga dengan tahanan atau hambatan, berfungsi untuk menghambat arus listrik yang melawatinya. Satuan harga resistor adalah Ohm. ( $1 \mathrm{M} \Omega$ (mega ohm $)=1000$ $\mathrm{K} \Omega($ kilo ohm $)=10^{6} \Omega(\mathrm{ohm})$ ) (Willem; 2013).

Resistor ada dua jenis, ada yang termasuk jenis karbon, ada yang dengan kabel. Keduanya tujuannya sama, perbedaan terletak pada jumlah watt yang dapat mereka tangani tanpa terbakar. Pada sirkuit transistor kita lebih banyak bekerja dengan resistor karbon karena arus pada kebayakan sirkuitnya cukup rendah (Stanley; 2003).

Kondensator atau sering disebut sebagai kapasitor adalah suatu alat yang dapat menyimpan energi di dalam medan listrik, dengan cara mengumpulkan ketidakseimbangan internal dari muatan listrik. Kondensator memiliki satuan yang disebut Farad dari nama Michael Faraday (Syaifi; 2017)

Tujuan dari penelitian adalah untuk mengetahui cara pembuatan simulasi pengisian air ketel menggunakan rangkaian Integrated Circuitagar dapat dijalankansecara manual dan otomatis dan mengetahui cara pembuatan sistem alarm pada simulasi pengisian air ketel menggunakan rangkaian Integrated Circuit.

\section{METODE}

Penelitian dilakukan selama pembuatan model simulasi pengisian air ketel menggunakan rangkaian integrated circuit, yakni terhitung tanggal 3 Oktober 2018 proses awal perancangan dan desain pembuatan model simulasi 
tersebut sampai dengan 2 November 2019.

Desain penelitian yang dipakai dalam penelitian adalah ekperimen One Shot Case Study yaitu sebuah eksperimen yang dilaksanakan tanpa adanya kelompok pembanding dan juga tanpa tes awal (Suharsimi, 2009). Pada penelitian ini adanya suatu perlakuan (X) berupa perancangan dan pembuatan alat pengontrolan air pada ketel dan pengendalian pompa dengan menggunakan integrated circuit logika dasar, selanjutnya dilakukan pengukuran kinerja (O) dari alat tersebut.

Fokus dari penelitian ini adalah pembuatan sistem kendali pompa untuk simulasi pengisian air ketel. Lokus penelitian ini adalah laboratorium listrik Politeknik Ilmu Pelayaran Semarang dan bengkel pribadi.

Sumber data yang digunakan dalam penelitian ini adalah sumber data primer dan sumber data sekunder. Sumber data primer didapatkan langsung dari sumbernya yaitu dengan cara pengamatan, pencatatan, serta wawancara dengan crew kapal MV. Tanto Setia. Sumber data sekunder didapat melalui buku-buku, dokumendokumen yang ada di kapal yang berkaitan dengan teknik digital dan teknik elektronika.

Teknik pengambilan data adalah cara pengumpulan data dengan memperoleh keterangan yang benar sehingga dapat dipertanggung jawabkan. Dalam penelitian ini teknik pengambilan data dengan pengukuran tegangan listrik.

Setelah dilakukan pengambilan data dari alat yang dibuat, maka hasil pengukuran dimasukan dalam tabel. Analisis ini dipakai untuk mengetahui bagaimana alat ini bekerja dengan baik, maka analisis yang digunakan adalah analisis deskriptif.

Pada perancangan pembuatan rangkaian elektronika sering mengalami kendala yaitu tingkat kerumitan yang tinggi dan memerlukan ketelitian, pemahaman serta ketekunan yang tinggi pula. Kesalahan dalam memasukan data bisa menyebabkan kegagalan total hasil rangkaian yang diharapkan.

Pada buku digital dan rancangan logika terdapat teori untuk perancangan rangkaian, terdiri dari beberapa komponen. Salah satunya adalah menggunakan rangkaian integrated circuit digital. Dengan berbagai kesulitan yang ada saat perancangan rangkaian dan penelitian maka pengumpulan data untuk pembuatan rangkaian elektronika ini dapat memberikan kemudahan dan pemahaman bagi peneliti untuk memberikan hasil akhir yang tepat dan akurat.

Gambar 1 menunjukkan alur piker penelitian mengenai gambaran obyek penelitian sebagai acuan dalam memecahkan masalah dan menguraikan simulasi pengisian air ketel menggunakan rangkaian integrated circuit gerbang logika dasar.

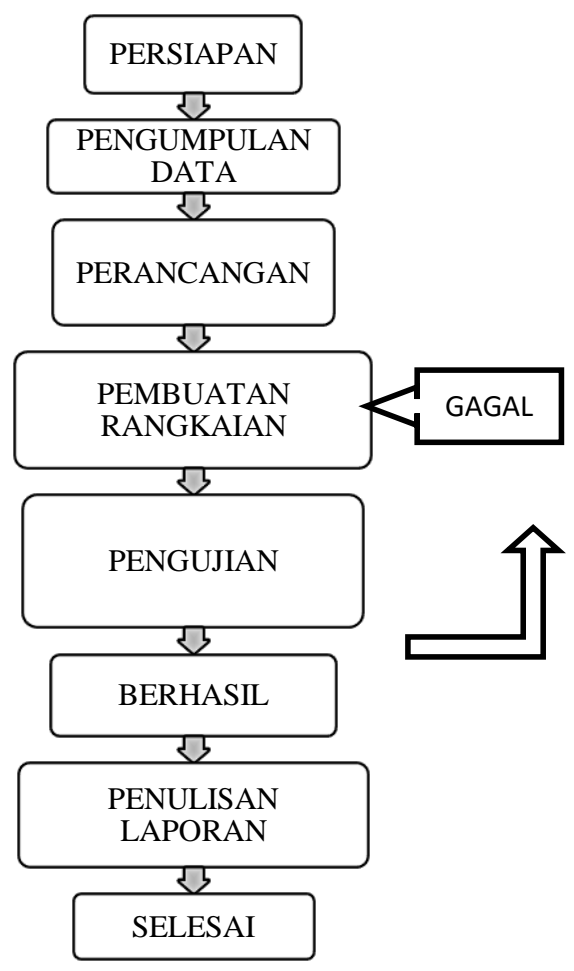

Gambar 1. Alur Pikir Penelitian

\section{III.HASIL DAN PEMBAHASAN}

Hasil pengukuran kaki pada integrated circuit saat kondisi air lowlow level dapat dilihat pada Tabel 1. 
Tabel 1. Hasil Pengukuran Saat Kondisi Air Low-low Level

\begin{tabular}{|c|c|}
\hline Kaki & Tegangan \\
\hline 1 & 0 \\
\hline 2 & 0 \\
\hline 3 & 9,8 \\
\hline 4 & 0,1 \\
\hline 5 & 9,8 \\
\hline 6 & 8,2 \\
\hline 7 & 0,15 \\
\hline 8 & 0 \\
\hline 9 & 0,12 \\
\hline 10 & 8,2 \\
\hline 11 & N/A \\
\hline 12 & N/A \\
\hline 13 & N/A \\
\hline 14 & 9,9 \\
\hline
\end{tabular}

Berdasarkan Tabel 1, kaki nomor 1 dan 2 adalah input yang memiliki besaran tegangan 0 Volt. Lalu output pada kaki nomor 3 memiliki besaran tegangan 9,8 Volt yang di teruskan menuju input kaki nomor 5 maka besaran tegangan pada kaki nomor akan sama bernilai 9,8 Volt. Kaki input nomor 6 memiliki besaran tegangan 8,2 Volt, kaki pada nomor 4 yang sebagai output menghasilkan besaran tegangan 0,1 Volt, kaki nomor 7 teganganya sebesar 0,15 Volt dihubungkan dengan ground. Kaki nomor 8 dan 9 adalah input dengan besaran tegangan 0 Volt dan 0,12 Volt menghasilkan tegangan output pada kaki nomor 10 sebesar 8,2 Volt sehingga arus listrik akan menuju ke transistor dan relay akan bergerak yang tadinya kondisi open menjadi close maka pompa akan beroperasi. Kaki nomor 14 bertegangan 9,9 Volt.

Hasil pengukuran kaki pada integrated circuit saat kondisi air low level dan menuju kondisi air high level dapat dilihat pada Tabel 2. Berdasarkan Tabel 2, kaki nomor 1 dan 2 adalah input memiliki besaran tegangan 6,8 Volt lalu output pada kaki nomor 3 memiliki besaran tegangan 0,4 Volt yang di teruskan menuju input kaki nomor 5 maka besaran tegangan pada kaki nomor akan sama bernilai 0,4 Volt. Kaki input nomor 6 memiliki besaran tegangan 8,3 Volt, lalu kaki pada nomor 4 yang sebagai output menghasilkan besaran tegangan 0,4 Volt. kaki nomor 7 teganganya sebesar $0,4 \quad$ Volt dihubungkan dengan ground. Kaki nomor 8 dan 9 adalah input dengan besaran tegangan 0,3 Volt dan 0,4 Volt menghasilkan tegangan output pada kaki nomor 10 sebesar 8,3 Volt sehingga arus listrik akan tetap menuju ke transistor dan pompa masih beroperasi mengisi ketel. Kaki nomor 14 bertegangan 10 Volt. Hasil pengukuran kaki pada integrated circuit saat kondisi air high level dapat dilihat pada Tabel 3 berikut ini.

Tabel 2. Hasil Pengukuran Saat Kondisi Air Low LevelMenuju Air High level

\begin{tabular}{|c|c|}
\hline Kaki & Tegangan \\
\hline 1 & 6,8 \\
\hline 2 & 6,8 \\
\hline 3 & 0,4 \\
\hline 4 & 0,4 \\
\hline 5 & 0,4 \\
\hline 6 & 8,3 \\
\hline 7 & 0,4 \\
\hline 8 & 0,3 \\
\hline 9 & 0,4 \\
\hline 10 & 8,3 \\
\hline 11 & N/A \\
\hline 12 & N/A \\
\hline 13 & N/A \\
\hline 14 & 10 \\
\hline
\end{tabular}

Berdasarkan Tabel 3, kaki nomor 1 dan 2 adalah input memiliki besaran tegangan 7,4 Volt lalu output pada kaki nomor 3 memiliki besaran tegangan 0,2 Volt yang diteruskan menuju input kaki nomor 5 maka besaran tegangan pada kaki nomor akan sama bernilai 0,2 Volt. Kaki input nomor 6 memiliki besaran tegangan 0,1 Volt, kaki pada nomor 4 yang sebagai output menghasilkan besaran tegangan 10,1 Volt. 
Tabel 3. Hasil Pengukuran Saat Kondisi Air High level

\begin{tabular}{|c|c|}
\hline Kaki & Tegangan \\
\hline 1 & 7,4 \\
\hline 2 & 7,4 \\
\hline 3 & 0,2 \\
\hline 4 & 10,1 \\
\hline 5 & 0,2 \\
\hline 6 & 0,1 \\
\hline 7 & 0,1 \\
\hline 8 & 7,7 \\
\hline 9 & 9,5 \\
\hline 10 & 0,1 \\
\hline 11 & N/A \\
\hline 12 & N/A \\
\hline 13 & N/A \\
\hline 14 & 10,6 \\
\hline
\end{tabular}

Kaki nomor 7 tegangannya sebesar 0 Volt dihubungkan dengan ground. Kaki nomor 8 dan 9 adalah input dengan besaran tegangan 7,7 Volt dan 9,5 Volt. Tegangan output pada kaki nomor 10 menjadi 0 Volt sehingga arus listrik tidak akan menuju ke transistor dan relay akan bergerak yang tadinya kondisi close menjadi open maka pompa akan berhenti beroperasi. Kaki nomor 14 bertegangan 10,6 Volt.

Tabel 4. Hasil Pengukuran Kaki Integrated Circuit Saat Kondisi Air Menuju Low Level

\begin{tabular}{|c|c|}
\hline Kaki & Tegangan \\
\hline 1 & 7,2 \\
\hline 2 & 7,2 \\
\hline 3 & 0 \\
\hline 4 & 9,6 \\
\hline 5 & 0 \\
\hline 6 & 0 \\
\hline 7 & 0,1 \\
\hline 8 & 0 \\
\hline 9 & 9,6 \\
\hline 10 & 0 \\
\hline 11 & N/A \\
\hline 12 & N/A \\
\hline 13 & N/A \\
\hline 14 & 10,5 \\
\hline
\end{tabular}

Berdasarkan Tabel 4, kaki nomor 1 dan 2 adalah input memiliki besaran tegangan 7,2 Volt lalu output pada kaki nomor 3 memiliki besaran tegangan 0
Volt yang diteruskan menuju input kaki nomor 5 maka besaran tegangan pada kaki nomor akan sama bernilai 0 Volt. Kaki input nomor 6 memiliki besaran tegangan 0 Volt, kaki pada nomor 4 yang sebagai output menghasilkan besaran tegangan 9,6 Volt. kaki nomor 7 teganganya sebesar 0 Volt dihubungkan dengan ground. Kaki nomor 8 dan 9 adalah input dengan besaran tegangan 0 Volt dan 9,6 Volt. Maka tegangan output pada kaki nomor 10 sebesar 0 Volt sehingga arus listrik tetap tidak akan akan menuju ke transistor dan pompa masih belum beroperasi. Kaki nomor 14 bertegangan 10,5 Volt.

Tabel 5. Hasil Pengukuran Kaki Integrated Circuit Saat Kondisi Air Low Level Pompa Nyala Kembali

\begin{tabular}{|c|c|}
\hline Kaki & Tegangan \\
\hline 1 & 0 \\
\hline 2 & 0 \\
\hline 3 & 9,8 \\
\hline 4 & 0,1 \\
\hline 5 & 9,8 \\
\hline 6 & 8,2 \\
\hline 7 & 0,15 \\
\hline 8 & 0,3 \\
\hline 9 & 0,12 \\
\hline 10 & 8,2 \\
\hline 11 & N/A \\
\hline 12 & N/A \\
\hline 13 & N/A \\
\hline 14 & 9,9 \\
\hline
\end{tabular}

Berdasarkan Tabel 5, kaki nomor 1 dan 2 adalah input yang memiliki besaran tegangan 0 Volt lalu output pada kaki nomor 3 memiliki besaran tegangan 9,8 Volt yang diteruskan menuju input kaki nomor 5 maka besaran tegangan pada kaki nomor akan sama bernilai 9,8 Volt. Kaki input nomor 6 memiliki besaran tegangan 8,2 Volt, kaki pada nomor 4 yang sebagai output menghasilkan besaran tegangan 0,1 Volt. kaki nomor 7 teganganya sebesar 0,15 Volt dihubungkan dengan ground. Kaki nomor 8 dan 9 adalah input dengan besaran tegangan 0,3 Volt dan 0,12 Volt meghasilkan tegangan pada output di kaki nomor 10 sebesar 8,2 Volt sehingga arus listrik akan menuju ke transistor dan 
relay akan bergerak yang tadinya kondisi open menjadi close maka pompa akan kembali beroperasi. Kaki nomor 14 bertegangan 9,9 Volt.

a. Pembuatan simulasi pengisian air ketel menggunakan rangkaian Integrated Circuit

Alat ini dikendalikan oleh integrated circuit gerbang logika dasar. Terdapat 7 jenis gerbang logika dasar yang membentuk sebuah sistem elektronika digital yaitu gerbang AND, gerbang OR, gerbang NOT, gerbang NAND, gerbang NOR, gerbang X-OR, dan gerbang X-NO. Untuk menentukan integrated circuit mana yang paling cocok maka langkah pertama yang harus dilakukan adalah menentukan gambaran logika menggunakan gambar dan tabel.

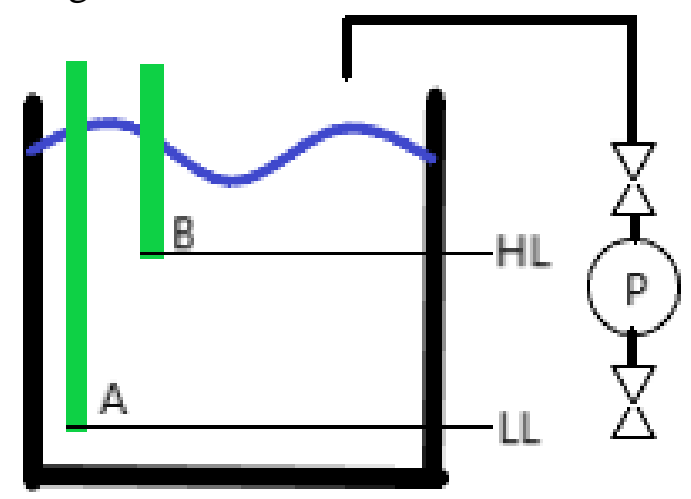

Gambar 2. Gambaran rencana menentukan logika

Keterangan gambar :

A : Sensor High Level

B : Sensor Low Level

$\mathrm{P}$ : Pompa

Gambar 2 bertujuan untuk mempermudah menentukan input apa saja yang akan dimasukan kedalam sistem pengendalian alat. Setelah mengetahui input yang dibutuhkan langkah selanjutnya membuat tabel kebenaran.
Tabel 6 Tabel Kebenaran

\begin{tabular}{|l|l|l|l|c|}
\hline $\mathrm{A}$ & $\mathrm{B}$ & $\mathrm{P}_{0}$ & $\mathrm{P}_{1}$ & Persamaan \\
\hline 0 & 0 & 0 & 1 & $\underline{A B C}$ \\
\hline 1 & 0 & 1 & 1 & $A \underline{B} C$ \\
\hline 1 & 1 & 1 & 0 & $\mathrm{ABC}$ \\
\hline 1 & 0 & 0 & 0 & $A \underline{B C}$ \\
\hline 0 & 0 & 1 & 1 & $\underline{A B C}$ \\
\hline
\end{tabular}

Keterangan Tabel :

A : Sensor High Level

B : Sensor Low Level

$\mathrm{P}_{0}$ : Pompa kondisi awal

$\mathrm{P}_{1}$ : Pompa kondisi akhir

Dari Tabel 6 kita mendapatkan persamaan dari pompa yang hasil akhirnya sama dengan 1 . Persamaan tersebut yaitu :

$$
Y=\underline{A B C}+\underline{A B} C+\underline{A B} C
$$

Keterangan persamaan :

Y : Hasil
A : Sensor High Level
B : Sensor Low Level
$\mathrm{C}$ : Kondisi awal

Dari persamaan tersebut di atas, kemudian disederhanakan dengan $\mathrm{K}$ Map 3 variabel, dimana K-map 3 variabel digunakan untuk persamaan $\mathrm{Y}=\underline{A B C}+A \underline{B} C+\underline{A B} C$ agar menjadi lebih ringkas dan dapat menentukan integrated circuit yang tepat.

Tabel 7 K-Map 3 Variabel

\begin{tabular}{|l|l|l|l|l|}
\hline$A / B C$ & 00 & 01 & 11 & 10 \\
\hline 0 & 1 & 1 & 0 & 0 \\
\hline 1 & 0 & 1 & 0 & 0 \\
\hline
\end{tabular}

Hasil

penyerderhanaan persamaan menggunakan K-Map 3 variabel yaitu :

$$
\begin{gathered}
\mathrm{Y}=\underline{A B}+\underline{B} C \\
\mathrm{Y}=\underline{B}(C+\underline{A})
\end{gathered}
$$


Keterangan persamaan :

Y : Hasil

A : Sensor High Level

B : Sensor Low Level

$\mathrm{C}$ : Kondisi awal

Atau persamaan di atas dapat disederhanakan dengan menggunakan persamaan aljabar sebagai berikut :

$$
\begin{aligned}
\mathrm{Y} & =\underline{A B C}+A \underline{B} C+\underline{A B C} \\
\mathrm{Y} & =\underline{B}(\underline{A C}+A C+\underline{A C}) \\
\mathrm{Y} & =\underline{B}(\underline{A C}+C(A+\underline{A}) \\
\mathrm{Y} & =\underline{B}(\underline{A C}+C(1) \\
\mathrm{Y} & =\underline{B}(\underline{A C}+\underline{ }) \\
\mathrm{Y} & =\underline{B}(C+\underline{C A}) \\
\mathrm{Y} & =\underline{B}(C+\underline{A}) \\
\mathrm{Y} & =\underline{B}(\underline{A}+\mathrm{C})
\end{aligned}
$$

Keterangan persamaan :

Y : Hasil
A : Sensor High Level
B : Sensor Low Level
$\mathrm{C}$ : Kondisi awal

Jadi hasil akhir penyederhanaan persamaan $\mathrm{Y}=\underline{A B C}+A \underline{B} C+\underline{A B} C$ menggunakan persamaan aljabar yaitu $\mathrm{Y}=\underline{B}(\underline{A}+\mathrm{C})$.

Pengubahan persamaan $\mathrm{Y}=\underline{B}(\underline{A}$ $+C)$ akan dijabarkan ke gerbang logika lain sebagai berikut :

$$
\begin{aligned}
& \underline{B}(\underline{A}+\mathrm{C})=\underline{B}(\underline{A}+C) \\
& \underline{B}(\underline{A}+\mathrm{C})=B+\underline{A}+C
\end{aligned}
$$

Hasil konversidari persamaan $\mathrm{Y}$ $=\underline{B}(\underline{A}+\mathrm{C})$ menjadi persamaan bentuk lain yaitu $\mathrm{Y}=B+\underline{A}+C$.

Persamaan $\mathrm{Y}=B+\underline{A}+\overline{C \text { ini jika di }}$ aplikasikan ke dalam gerbang logika NAND menjadi seperti berikut :

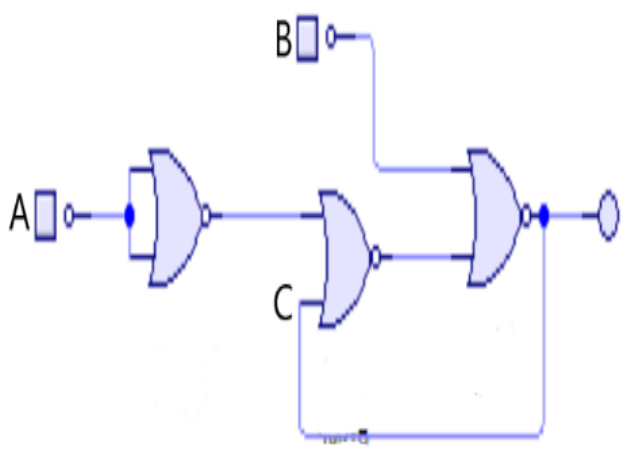

Gambar 4 Rangkaian persamaan

$$
\mathrm{Y}=\underline{B+\underline{A}+C}
$$

Keterangan :

A : Input low water level

B : Input high water level

C : Input kondisi awal dan akhir

Menggunakan gerbang NOR hanya membutuhkan 3 gerbang logika, tentunya dari persamaan $\mathrm{Y}=$ $B+\underline{A}+C$ bisa menggunakan 1

integrated circuit saja yaitu IC4001 tentunya hal ini akan lebih efisien dalam rangkaiannya.Setelah mendapatkan rangkaian integrated circuit yang tepat langkah selanjutnya yaitu menyambungkan output dari integrated circuit tepatnya kaki nomor 10 akan di sambungkan ke transistor. Jika output bernilai 1 maka transistor akan mengalirkan tegangan relay. Hal tersebut akan mengakibatkan relay yang kondisi awalnya open menjadi close maka pompa akan beroperasi mengisi ketel.

Perancangan

rangkaian elektronika dengan project board. Breadboard adalah projectboard atau yang sering disebut dengan PCB (Printed Circuit Board) sementara yang dapat digunakan untuk eksperimen suatu desain rangkaian elektronika. Breadboard dapat digunakan untuk mengalisa komponen yang salah dalam sebuah rangkaian eksperimen. Papan ini 
tidak memerlukan proses mensolder. Karena papan ini solderless alias tidak memerlukan solder sehingga dapat digunakan untuk prototype sementara, serta membantu dalam berekperimen desain sirkuit elektronika. Dalam penggunaan breadboard, komponen elektronika cukup ditancapkan dilubang-lubang yang terdapat pada breadboard.

Dalam pembuatan pengendalian alat pengisian air ketel penulis menggunakan breadboard karena sangat cocok dengan pembuatan rangkaian elektronika, mudah digunakan, dan jika terjadi kesalahan rangkaian masih bisa dipakai kembali. Berikut gambar susunan rangkaian elektronika pada papan breadboard :
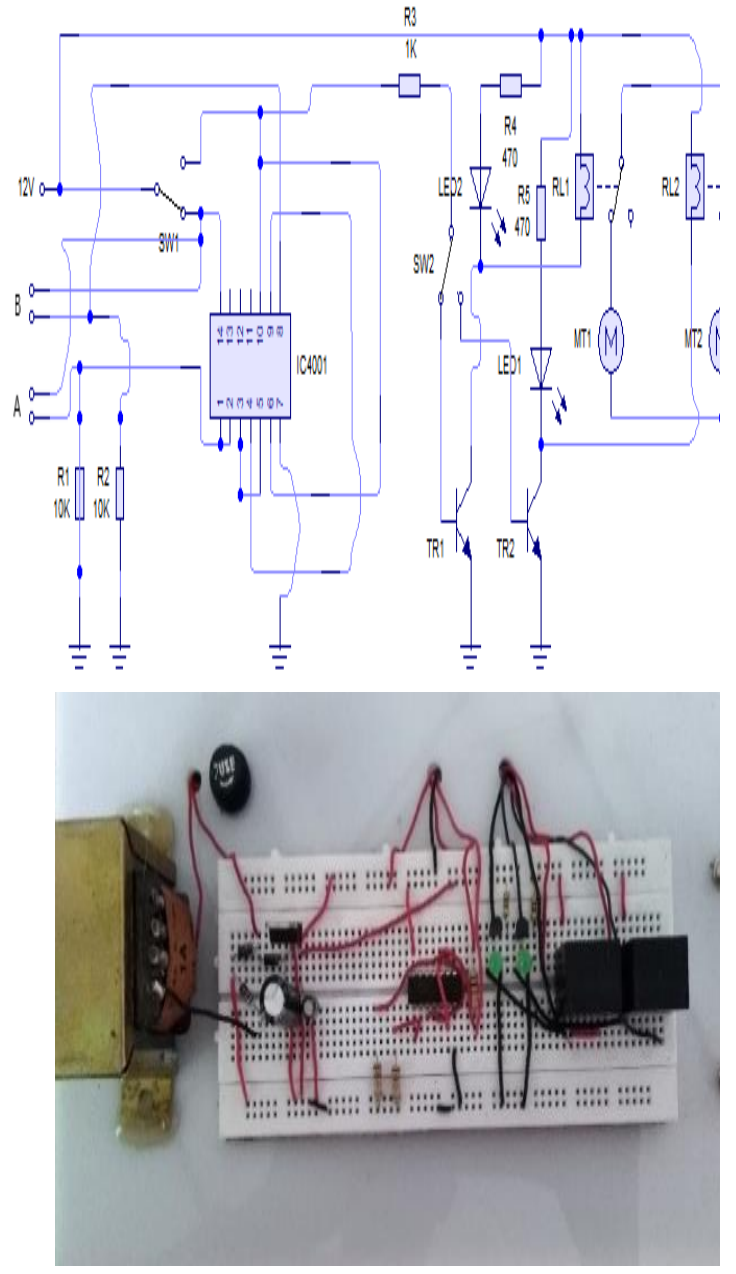

Gambar 5 Rangkaian komponen pada breadboard
Pada rangkaian tersebut terdapat kabel-kabel penghubung antara komponen elektronika satu dengan yang lain. Nama kabel penghubung antara komponen satu dengan yang lain disebut jumper.

b. Cara mengatur pengisian air ketel secara manual dan otomatis

Cara mengatur pengisian air ketel secara manual ataupun otomatis menggunakan switch (saklar) on off on. Saklar ini memiliki 3 kaki. Kaki tengah sebagai input dari sumber listrik dan salah satu dari kaki yang lain meneruskan arus listrik sesuai yang dipilih melalui saklar.

Setelah sistem ini dirancang maka mengatur pengisian air ketel secara manual ataupun otomatis hanya dengan memindah saklar kesalah satu pilihan yang di inginkan.

c. Membuat sistem alarm pengisian air ketel menggunakan ragakaian Integrated Circuit

Alat ini akan dikendalikan oleh integrated circuit gerbang logika dasar. Karena terdapat 7 jenis integrated circuit untuk menentukan integrated circiut yang paling cocok maka langkah pertama adalah menentukan gambaran logika menggunakan tabel kebenaran. Tabel akan di isi dengan angka 1 yang berarti on dan angka 0 yang berarti off.

Tabel 8 Tabel Kebenaran

\begin{tabular}{|c|c|c|c|}
\hline $\mathrm{A}$ & $\mathrm{B}$ & $\mathrm{Y}$ & Persamaan \\
\hline 0 & 0 & 1 & $\underline{A B}$ \\
\hline 0 & 1 & 1 & $\underline{A B}$ \\
\hline 1 & 0 & 0 & $\bar{A} \underline{B}$ \\
\hline 1 & 1 & 1 & $\mathrm{AB}$ \\
\hline
\end{tabular}

Keterangan tabel :
A : Sensor Low Level Alarm
B : Sensor High Level Alarm
Y : Kondisi Alarm 
Dari tabel 8 tersebut kita mendapatkan persamaan aljabar yaitu

$$
\mathrm{Y}=\underline{A B}+\underline{A} B+A B
$$

Keterangan persamaan :

A : Sensor Low Level Alarm

B : Sensor High Level Alarm

$\mathrm{Y}$ : Kondisi Alarm

Dari persamaan di atas, persamaan tersebut dapat di sederhanakan menggunakan hukum persamaan aljabar sebagai berikut :

$\mathrm{Y}=\underline{A B}+\underline{A} B+A B$

$\mathrm{Y}=(\underline{A B}+A B)+\underline{A B} . . \quad$ Hukum

Komutatif

$\mathrm{Y}=(1)+\underline{A} B \quad$....Jika dengan pembaliknya

$\mathrm{Y}=\underline{A} B$ Teorema

$\mathrm{Y}=\underline{A} B$ Dualitis

$\mathrm{Y}=(A+\underline{B})$ Inverter Ganda Hukum De

Morgan

Jadi Hasil akhir penyederhanaan persamaan $\mathrm{Y}=\underline{A B}+\underline{A} B+A B$ menggunakan hukum persamaan aljabar yaitu $\mathrm{Y}=(A+\underline{B})$. Dari persamaan tersebut akan di aplikasikan ke dalam gerbang logika untuk sistem alarm pada alat simulasi pengisian air ketel. Rangkaian Logikanya menjadi seperti berikut:

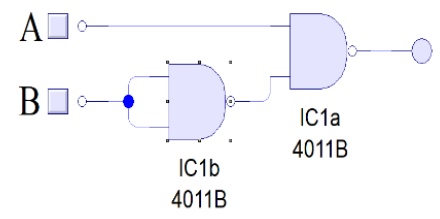

Gambar 6. Rangkaian persamaan $\mathrm{Y}=$

$$
\underline{(A+\underline{B})}
$$

Keterangan :

A : Sensor Low Level Alarm

B : Sensor High Level Alarm

Pada sistem alarm pengisian air ketel kondisi low level maka nilai A dan B adalah 0. Gerbang logika IC1b akan menghasilkan keluaran bernilai 1 maka gerbang logika ICla memiliki nilai masukan 0 dan 1 .

Nilai masukan tersebut manghasilkan nilai keluaran bernilai 1 . Hal ini akan menyebabkan alarm berbunyi.

Setelah ketel terisi air dan mencapai low level maka A akan bernilai 1 dan gerbang logika IC1a memiliki nilai masukan 1 dan 1 . Nilai masukan tersbeut akan menghasilkan nilai keluaran 0 . Hal ini akan meyebabkan alarm tidak berbunyi.

Saat air mecapai high level alarm maka sensor IC1b akan menghasilkan keluaran bernilai 0 dan gerbang logika IC1a memiliki nilai masukan 1 dan 0 . Nilai masukan tersebut menghasilkan nilai keluaran bernilai 1 maka alarm akan berbunyi disaat kondisi air high level.

Persamaan $\mathrm{Y}=(A+\underline{B})$ ini hanya untuk alarm low level dan high level saja. Untuk menambahkan alarm low low level maka membuat persamaan baru yaitu $\mathrm{Y}=\underline{C}$. Jika di aplikasikan ke dalam gerbang logika menjadi :

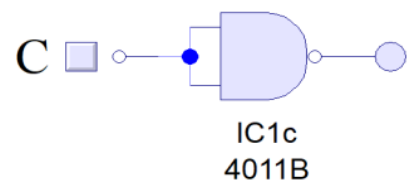

Gambar 7. Rangkaian persamaan $\mathrm{Y}=\underline{C}$ Keterangan :

$\mathrm{C}$ : Input low low water level alarm Setelah mendapatkan rangkaian integrated circuit yang tepat langkah selanjutnya yaitu menyambungkan integrated circuit dengan komponen yang lain. Rangkaiannya dapat dilihat dibawah ini.

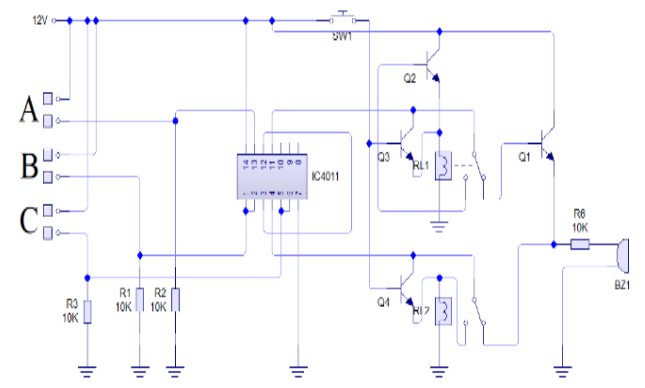

Gambar 8 Rangkaian sistem alarm pengisian air ketel

Keterangan :

A : Sensor low water level 
B : Sensor high water level

$\mathrm{C}$ : Sensor low low water level

\section{IV.SIMPULAN}

Simulasi pengisian air ketel ini menggunakan kendali IC NOR 4001, tegangan kaki masukan (input) dipengaruhi oleh water level dan keluaran (output) menggerakan relay. Pada hasil pengukuran pompa bekerja saat tegangan output kaki nomor 10 adalah 8,2 V. Saat air ketel penuh pompa tidak bekerja dan tegangan output kaki nomor 11 adalah 0.1 V. Rangkaian simulasi pengisian air ketel menggunakan integrated circuit gerbang logika lebih sederhana maka tingkat pemahaman bagi pemula dapat cepat dimengerti.Rangkaian ini dapat digunakan menggunakan 2 (dua) mode yaitu otomatis dan manual caranya cukup memindahkan saklar sesuai pilihan yang diinginkan. Saat menggunakan mode manual maka saklar nomor 1 akan memindah jalur aliran listrik agar tidak melewati integrated circuit maka pompa tidak akan terpengaruh oleh sensor yang ada pada ketel. Sedangkan saat mode otomatis saklar akan memindah jalur listrik menuju integrated circuit maka pompa akan beroperasi sesuai dengan keadaan water level pada ketel.

Bunyinya alarm dipengaruhi oleh water level dan pada pembuatan rangkaiannya menggunakan IC NAND 4011. Sensornya dipengaruhi oleh tinggi air. Jika air mengenai sensor maka sensor akan memberikan sinyal masukan kepada IC dan IC akan menerjemahkan apakah alarm berbunyi atau tidak.

\section{DAFTAR PUSTAKA}

Abdurrahman, Syaifi. 2017. Modul Elektronika Dasar, Direktorat
Pembinaan Sekolah Menengah

Kejurusan, Jakarta

Arikunto, Suharsimi. 2009. Manajemen Penelitian, Rineka Cipta, Jakarta.

Beuaty. Darmawansyah, Agung., dan Julius M. 2009. "Perancangan Rangkaian Terpadu Penguat Operasional Untuk Pengatur Nada" dalam Jurnal EECCIS Vol. III (hlm 17-22). Malang : Universitas Brawijaya

Handoyono, Jusak Johan. 2016. Ketel Uap, Turbin Uap, \& Turbin Gas Penggerak Utama Kapal. Jakarta; Djangkar.

Parinduri, Ikhsan dan Hutagalung, Siti Nurhabibah. 2018. "Perangkaian Gerbang Logika Dengan Menggunakan MATLAB (SIMULINK)" dalam Jurnal Teknologi dan Sistem Informasi Vol. V (hlm 63-70). Asahan : STMIK Royal Kisaran.

Siregar, Helmi Fauzi dan Parinduri, Ikhsan. 2017. "Prototype Gerbang Logika (AND, OR, NOT, NAND, NOR) Pada Laboratorium Elektronika STMIK Royal Kisaran" dalam Jurnal Teknologi Informasi (JurTI) Volume 1 (hlm. 38-47). Asahan : Universitas Asahan

Stanley, J.A. 2003. Pengenalan Elektronika Untuk Pemula, Bandung: CV. Pioner Jaya.

Widjanarka, Wijaya. 2006. Teknik Digital, Jakarta : Erlangga.

Willem. 2013. Teknik Listrik Dasar Otomotif, Jakarta : Direktorat Jenderal Peningkatan Mutu Pendidikan \& Tenaga Kependidikan.

https://teknikelektronika.com/. Diakses pada tanggal 22 November 2019 